\title{
DEVELOPMENT OF ADAPTIVE STRUCTURE BY VARIABLE GEOMETRY TRUSS (APPLICATION OF MOVABLE MONUMENT IN EXPO 2005)
}

\author{
Fumihiro Inoue \\ Technical Research Institute, Obayashi Corporation \\ 4-640 Shimokiyoto, Kiyose-shi, Tokyo Japan \\ inoue.fumihiro@obayashi.co.jp \\ Ryuichi Moroto \\ Technical Research Institute, Obayashi Corporation \\ 4-640 Shimokiyoto, Kiyose-shi, Tokyo Japan \\ moroto.ryuichi@obayashi.co.jp
}

\author{
Kohei Kurita \\ Technical Research Institute, Obayashi Corporation \\ 4-640 Shimokiyoto, Kiyose-shi, Tokyo Japan \\ kurita.kohei@obayashi.co.jp \\ Noriyuki Furuya \\ Technical Research Institute, Obayashi Corporation \\ 4-640 Shimokiyoto, Kiyose-shi, Tokyo Japan \\ furuya.noriyuki@obayashi.co.jp
}

\begin{abstract}
This paper describes the large-scale movable monument exhibited at the International Expo 2005, Aichi, Japan, as the first application of an adaptive structure using a VGT mechanism. This monument is composed of three identical movable towers comprising four truss members combined by VGT at joints. The VGT is an adaptive truss with an extensible actuator, so the monument's shape can be changed variably by controlling the length of each of its extensible actuators. In the application of the VGT to the movable monument, security against accidents was examined and authorization for the structure's design was acquired. Further, the control system's safety mechanism, management and operation manual were studied and approved. During the 185 days of the Expo, the monument was operated continuously for about 13 hours a day, and there was not a single breakdown or accident. Continuous safe and excellent performance was achieved, and the monument received high appraisal from promoters and many attendees.
\end{abstract}

Keywords: Variable Geometry Truss, Adaptive Structure, Movable Monument, Safe Mechanism, Expo2005 Aichi Japan

\section{INTRODUCTION}

Expo 2005 in Aichi, Japan ended successfully last year, with more than two million people attending from around the world. There were various exhibitions, entertainments, attractive buildings, new technology and events based on the theme of "Nature's wisdom". One remarkable technology displayed at the Expo was the application and performance of automated robots. For example, music-playing robots in a group, automatic cleaning robots, guard robots, etc. These scenes might be imagined a the future and such technologies continue to be developed.

In the Japanese zone of the Aichi prefecture pavilion near the center of the exhibition, as indicated in Figure 1, there was a large monument in the shape of a traditional Karakuri doll beckoning visitors inside. The exhibit here was called "Dancing Tower with Karakuri doll Performance", and was exhibited as a symbol of Aichi district's culture, harmonizing traditional technology with revolutionary new ones. Here also, robots were seen in action, which further enhanced the Expo.

The movable monument was an adaptive structure comprising Variable Geometry Trusses (called "VGT”). It looked like a large-scale multiple-joint manipulator. The VGT was a truss structure composed of extensible members, fixed members and hinges. By controlling the lengths of the extensible members, it was possible to create various truss shapes. The VGT was originally developed as an actuator for a spread-type universe construction in space,

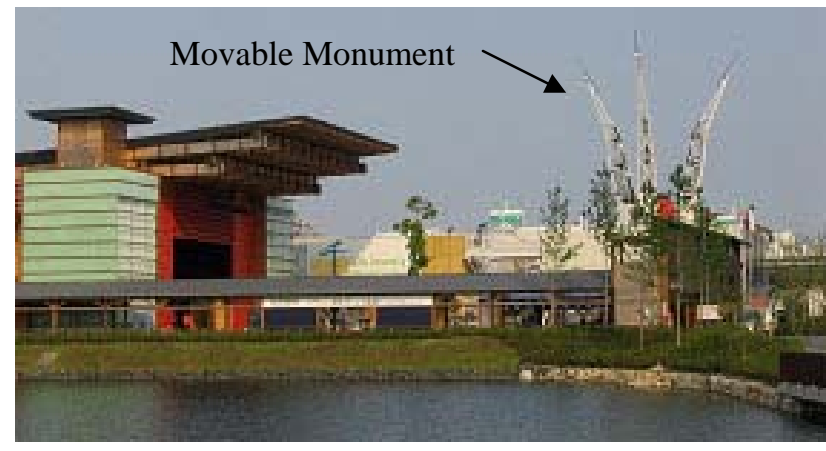

Figure 1 Aichi prefecture pavilion in the Japanese zone

and it was equipped with a small motor to perform various tasks. Thus, the VGT was considered to be a useful structural tool as a redundant intelligent structure ${ }^{[1,2]}$.

The authors have been studying and developing an adaptive structure using VGT ${ }^{[3,4]}$. An example of a shape change that combines two-dimensional VGTs in a beam is shown in Figure 2 (a). Simultaneously extending the extensible members makes the structure change like a spring stretching (b). Extending alternate extensible members makes the truss structure change to a circular shape (c). Moreover, extending them optionally and controlling the lengths of the extensible members, the truss beam can be changed into any intended shape (d).

As the example such VGT applications, a semi-empirical dome with an open roof and of variable shape, an artistic movable monument equipped with artificial intelligence 
harmonizing with its surroundings and an automatic reflection panel in music hall to suit the stage contents can be proposed. In future, this kind of movable structure is expected to have wide practical application with its active and flexible motion by incorporating artificial intelligence and information technology.

In this paper, as a first application of an adaptive structure using VGT, a large-scale movable monument was exhibited at the International Expo 2005, Aichi, Japan. The monument's development, tower structure design, safe control system and performance programs, and manufacture and construction at the site are explained in detail. Furthermore, the operation condition at the Expo and its overall results are reported.

\section{OUTLINE OF MOVABLE MONUMENT}

\subsection{Background and Outline of Development}

For the Nagakute Aichi prefecture pavilion, the Expo organizers requested a design for a monument comprising a symbol tower to attract visitors to the pavilion. We proposed a movable monument whose shape could be changed variably and irregularly. A large movable monument using VGT was selected as a very unique and attractive monument.

A picture of the Expo site and the Nagakute Aichi Prefecture pavilion where the movable monument was set up is shown in Figure 3, and the movable monument is outlined in Table 1 . The pavilion was in a picturesque position in the Japanese zone at the center of the Expo site. It faced a Japanese garden and the Kaede pond. It was located in front of the west gate and beside a global loop, making visitor access easy. The pavilion consisted of a festival plaza, a large-scale theater and a stage, a large area of the Cyube exchange pavilion, and an administration building. The exhibit contained the movable monument was built on the roof of the house.

The entire exhibit was composed of movable towers and an annexed device of a Karakuri doll. Each exhibit was united by an internal control signal, and various performances by both the monument and the Karakuri doll were planned.

\subsection{Design of Movable Monument}

Figure 4 shows schematic pictures of the entire movable monument and its base structure. The whole was composed of three movable iron towers of the same specification, and were spaced at 120-degree intervals around the circumference. Each tower comprised four truss members combined by VGT at joints. Each frame comprised a solid truss structure. The outside of the frame was equipped with a hinge, the inside combined slide actuator, and the shape of towers was changed in proportion to actuator length. Moreover, head illumination was provided at the point of the monument, and a artistic lightning rod was set up. A Karakuri device covered with a large lantern case was constructed at the center of the monument. The towers were seated on a base plate and were combined with long steel
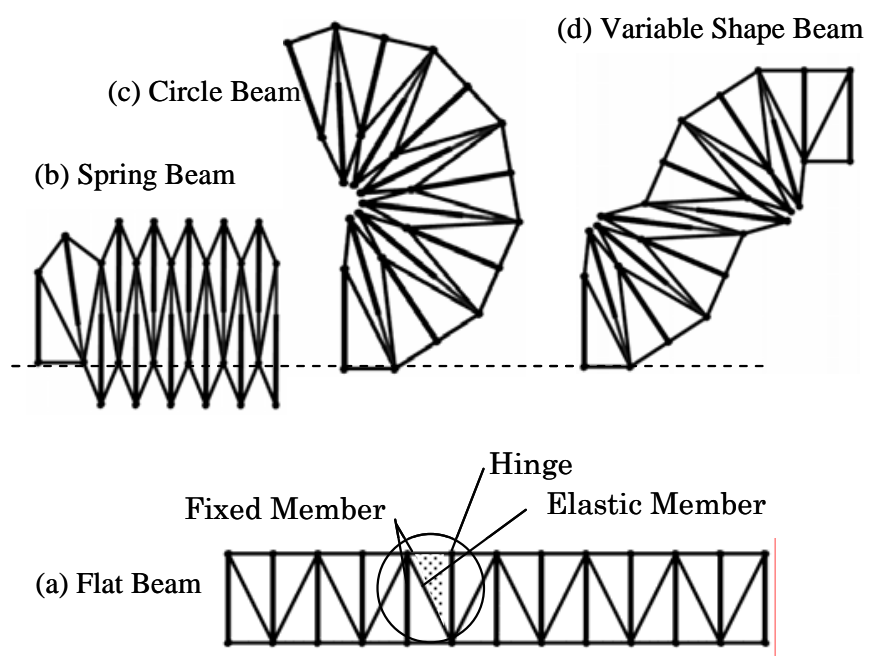

Figure 2 Basic transformation of beam shape using VGT

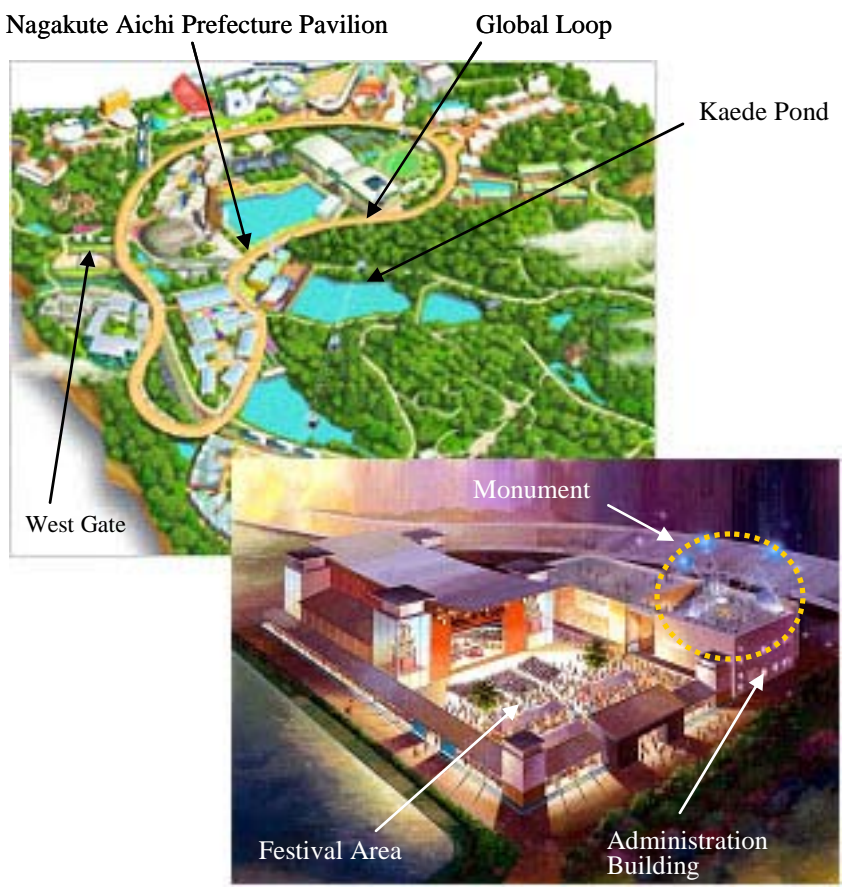

Figure 3 Overall Map of Expo site and Nagakute Aichi prefecture pavilion

(From the pamphlet of Aichi prefecture pavilion)

Table 1 Outline of Movable Monument

\begin{tabular}{c|c}
\hline $\begin{array}{c}\text { Construction } \\
\text { location }\end{array}$ & $\begin{array}{c}\text { Nagakute Aichi prefecture pavilion } \\
\text { in Expo 2005 }\end{array}$ \\
\hline Main use & Movable monument \\
\hline $\begin{array}{c}\text { Structure } \\
\text { classification }\end{array}$ & Steel structure with adaptive actuator \\
\hline Base condition & Combination steel base on the rooftop \\
\hline Maximum height & $\begin{array}{c}\text { Ground height }: 26.6 \mathrm{~m} \\
\text { Monument height; } 18.0 \mathrm{~m}\end{array}$ \\
\hline Construction period & From 2004. 11.1 to 20053.20 \\
\hline Operation period & From 2005. 3.25 to 20059.25 \\
\hline
\end{tabular}




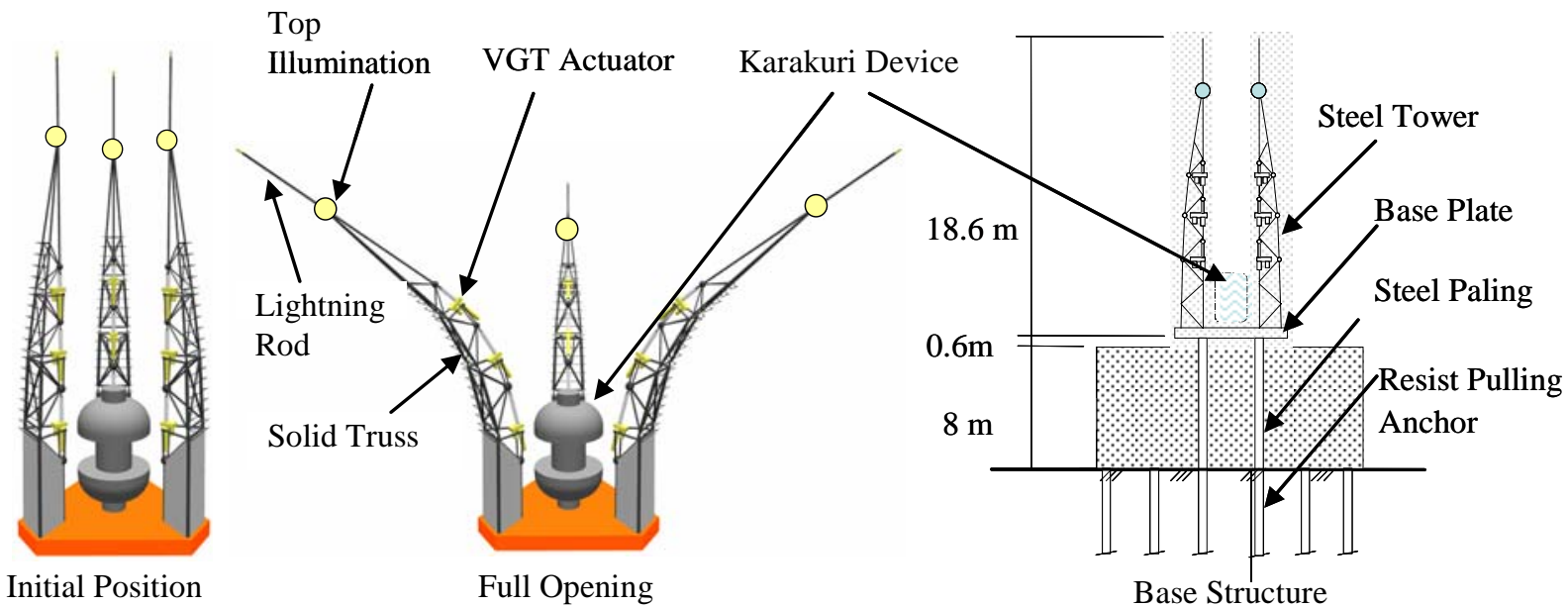

Figure 4 Schematic pictures of entire movable monument and base structure

paling that penetrated through the inside of the administration building to an anchor.

\subsection{Structure Design}

In the movable structure's design, it was necessary to ensure adequate security. Then, the evaluation of the structure's design and its performance was acquired from the designated organizations. For design, the earthquake force for a projection on the rooftop and the wind loading based on the regional average wind velocity were used. A section shape was selected to ensure security and the specification of the VGT actuator was decided. Moreover, the control system for the movable mechanism, the safety mechanism, the management and the operation system were examined and approved.

\section{VGT MECHANISM AND CONTROL SYSTEM}

\subsection{VGT Actuator and Structure}

Figure 5 shows the arrangement of the VGT actuator and the movable range of the tower. Three different sized VGT actuators were set up in each tower and were controlled independently. There were two VGT mechanism arrangements: pier type and chord type. In this tower, the chord type arrangement was adopted because it had advantages of higher rigidity, higher accuracy and lower actuator load. The rotation angle of the VGT mechanism was from 2.5 degrees inside to 18 degrees outside. Thus, the total maximum rotation angle of a tower equipped with three VGT mechanisms was from 7.5 degrees inside to 54 degrees outside.

Figure 6 shows a picture of the inner structure of an extensible actuator used in a VGT Mechanism. The actuator was of the electronic type in which a screw rod was geared to a servomotor through a ball screw and a wheel gear. The top of the screw rod was linked with a truss node and the body of the actuator was carried by trunnion joints. The support bars on the node were moved in the outer stopper. Even if the screw rod broke, the tower's safety could be maintained by the support bars. In the servomotor, a magnetic brake and an encoder detect the rotating angle.

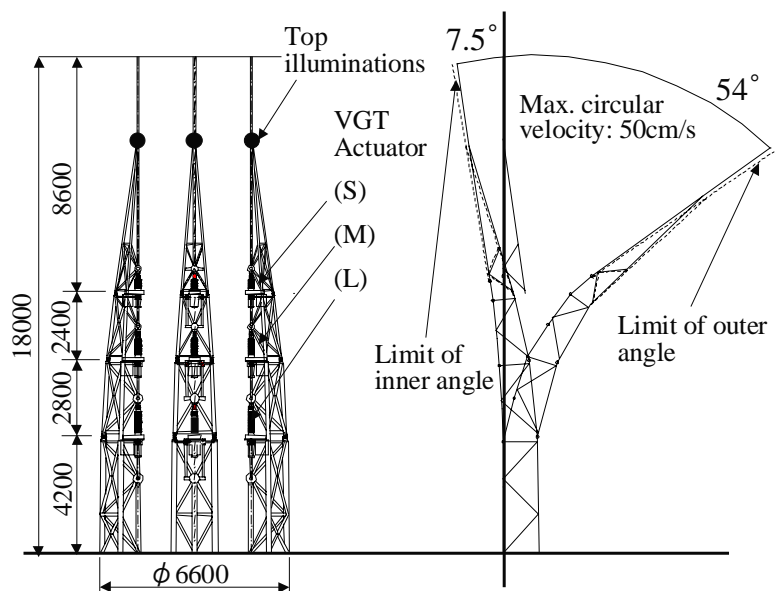

Figure 5 The arrangement of VGT actuator and the movement range of tower

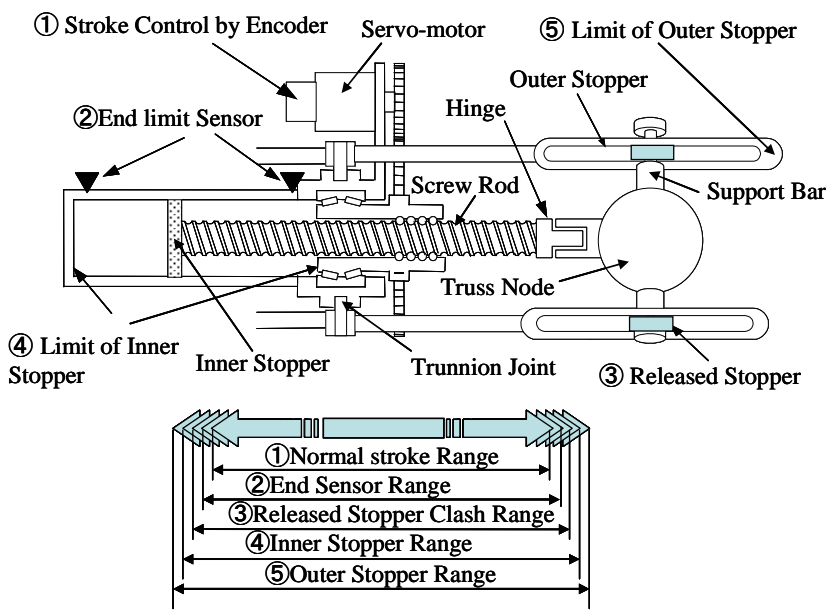

Figure 6 Inner structure of the extensible actuator of VGT and safe mechanisms

On the rod cover, both top and end limit sensors were installed. The motor was covered with waterproof covers. A cooling fan was maintained a suitable motor temperature. The electronic actuator had the advantage of high performance and energy conservation. 


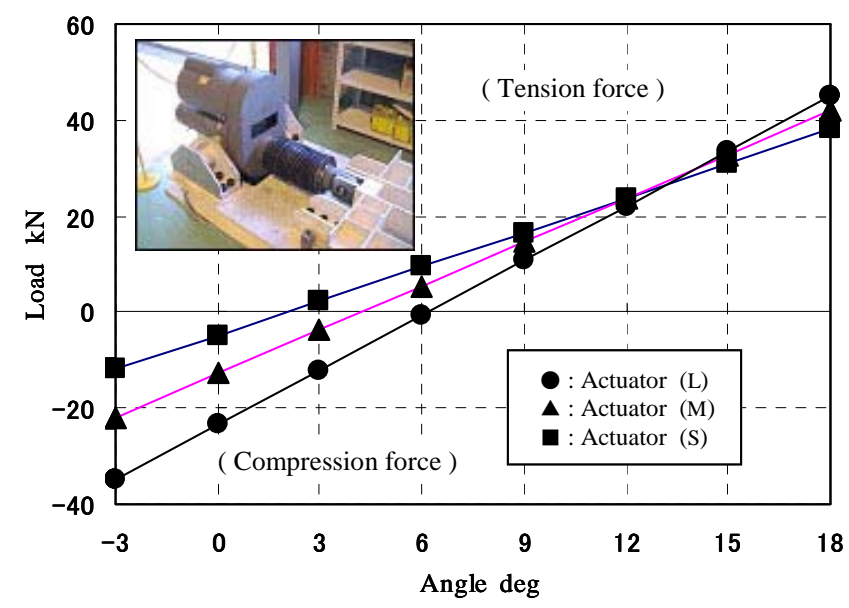

Figure 7 Relation between load acting on rod and angle of each VGT mechanism

The relation between the load acting on the rod and the angle of each VGT mechanism are indicated in Figure 7 when the tower's movement analyzed by numerical simulation at the same angle. The load values were almost proportional to the angle, and the tension force range was wide and high. The rod's peak velocity was $20 \mathrm{~mm} / \mathrm{s}$, the tower tip rotation velocity became $500 \mathrm{~mm} / \mathrm{s}$ or more when three VGT were operating at the same time. The tower movement could be expressed in an extremely dynamic and massive way in comparison with a conventional monument.

\subsection{Safety Mechanism and Control System}

The movable monument used at the Expo had to operate continuously, so a safe structure and control system had to be developed. The actuator rod stroke was detected by the servomotor encoder data and the actuator condition was continually monitored. Various accidents to the monuments were assumed, and the check points and safety mechanisms indicated were introduced. For an accident concerning rod stroke, a five-step safety mechanism was introduced.

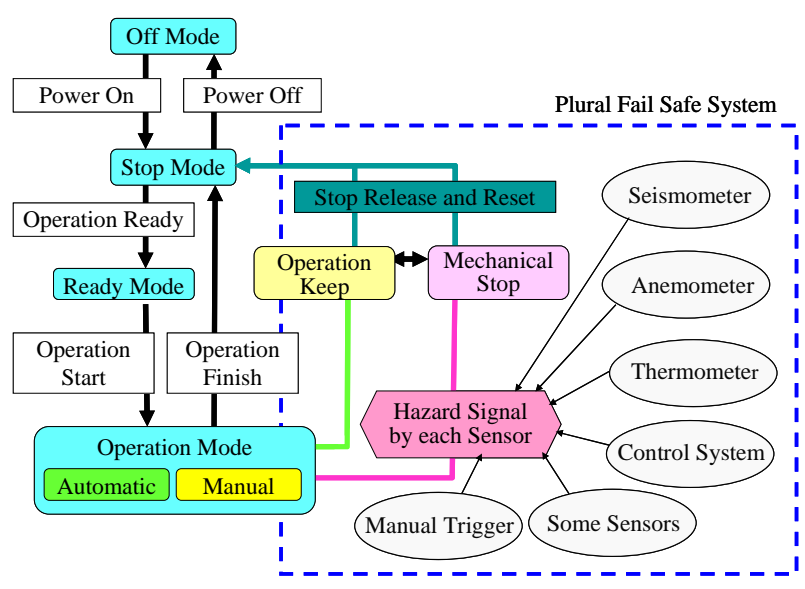

Figure 8 Flowchart of operation system and monument safety system

Figure 8 shows a chart of the operation system and plural fail-safe system. Monument operation was automated, except the initial process, and the operator mainly observed the system's safety confirmation and maintenance control. The plural fail-safe system that maintained monument safety was developed to avoid accidents. Furthermore, an emergency device; an automatic stop and warning device for earthquakes, thunderstorms, strong winds and heavy rain; and a backup device for power failure were installed.

\section{MONUMENT CONSTRUCTION}

Figure 9 shows the schedule for the monument's manufacture and construction. After the detailed design had been finished, the main body frame and base plate were manufactured, the equipment was selected and the VGT actuators were assembled concurrently. Before the monument was installed at the Expo site, a trial test of a monument tower, control system and performance program were carried out in the factory.

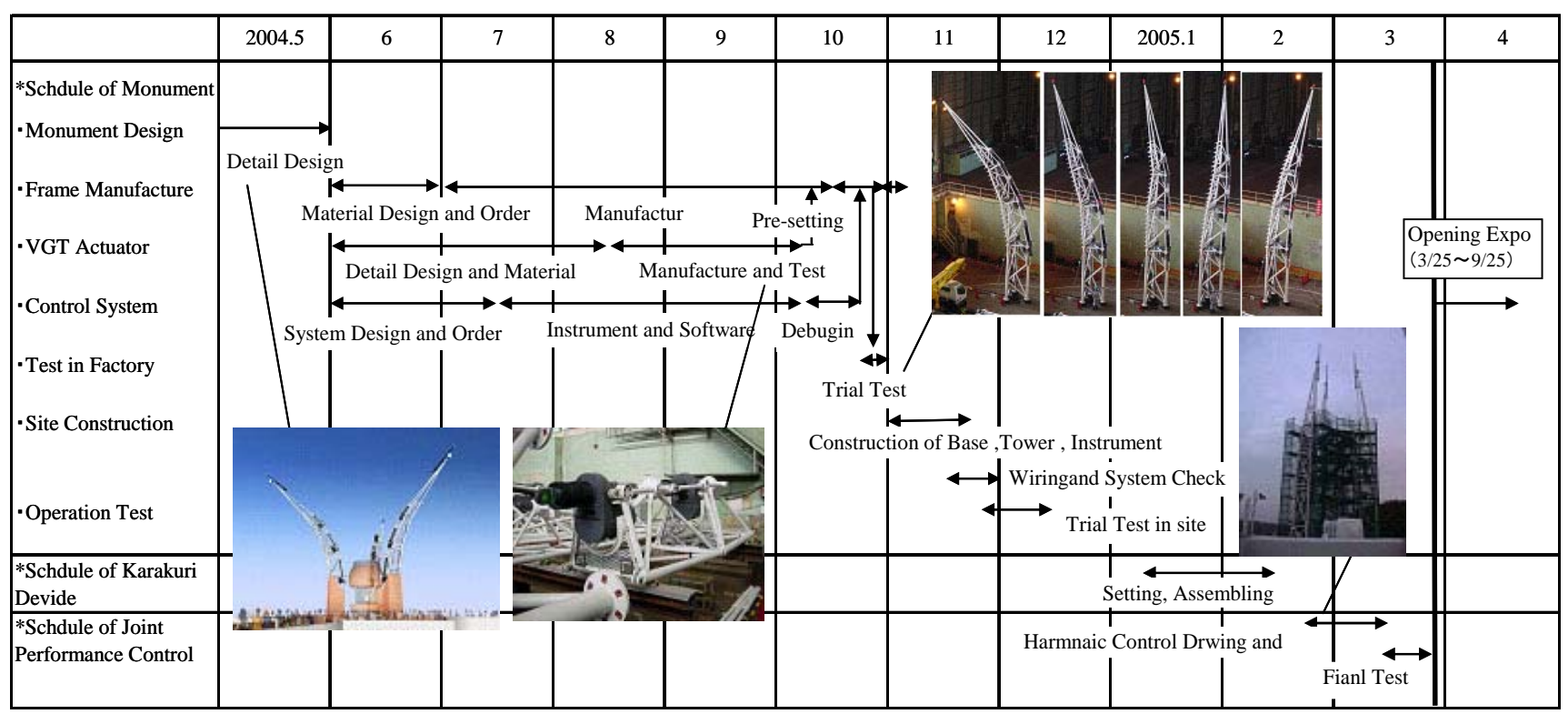

Figure 9 Schedule for monument manufacture and construction 


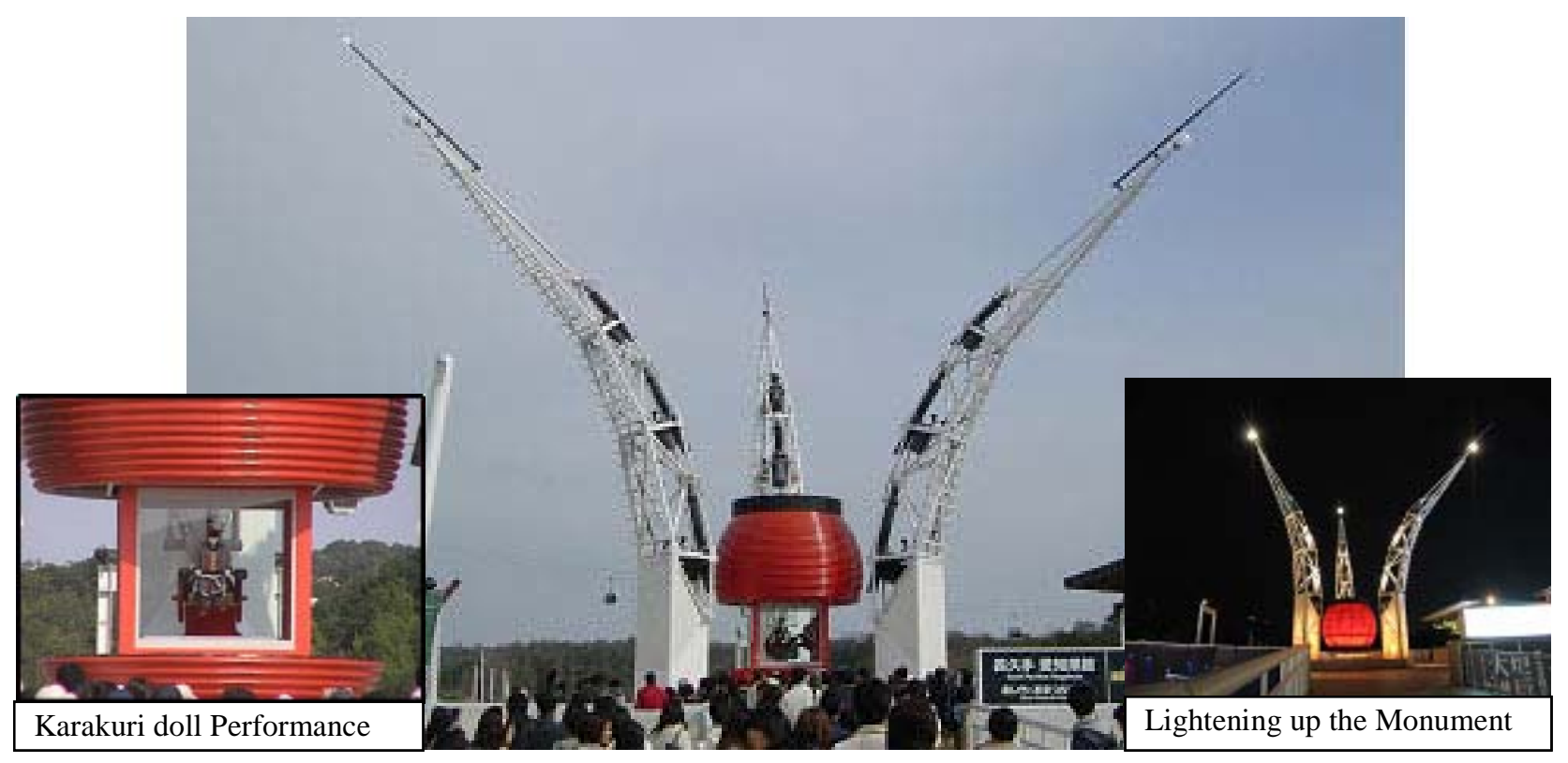

Figure 10 Overview of movable monument at Expo

Monument installation began at the site in November, 2005. Next, the electric wiring and control system were installed, and final operation was adjusted. This was all finished within the year. Furthermore, assembly and construction of the Karakuri device began in January, 2006. The program to verify the performance of the movable monument together with that of the Karakuri doll was adjusted at the end of February.

Final adjustment and examination for the Expo opening, and total system integration of both the Karakuri device and the monument were completed by the middle of March. Next, the operators were instructed of the monument's operation, management, and maintenance. The movable monument was handed over as an exhibition to the promoter for Aichi prefecture.

\section{PERFOMANCE AND OPERATION CONDITIONS}

An overview of the movable monument at Expo is shown in Figure 10. This picture expresses the coordinated performance of the three towers of the monument when fully opened, and Karakuri doll dancing in the center. A lot of visitors gathered around the monument, and they enjoyed the performance of the two exhibitions. Further, the monument was illuminated at night and its fantastic movements could be observed in the dark.

\subsection{Performance Patterns and Shape Change}

Figure 11 shows the monument's shape changes according to performance patterns. One loop of the total performance was composed of two patterns every 30
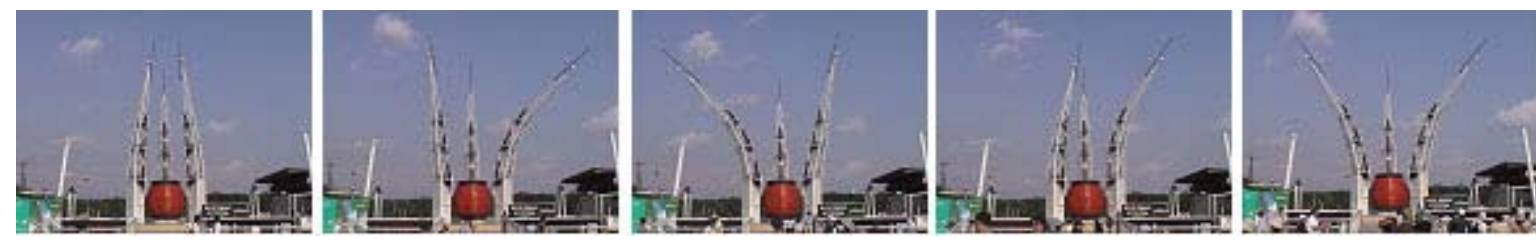

Start of monument performance

(a) Random Shape performance of the monument by natural data (25 min.)

Finish of

performance

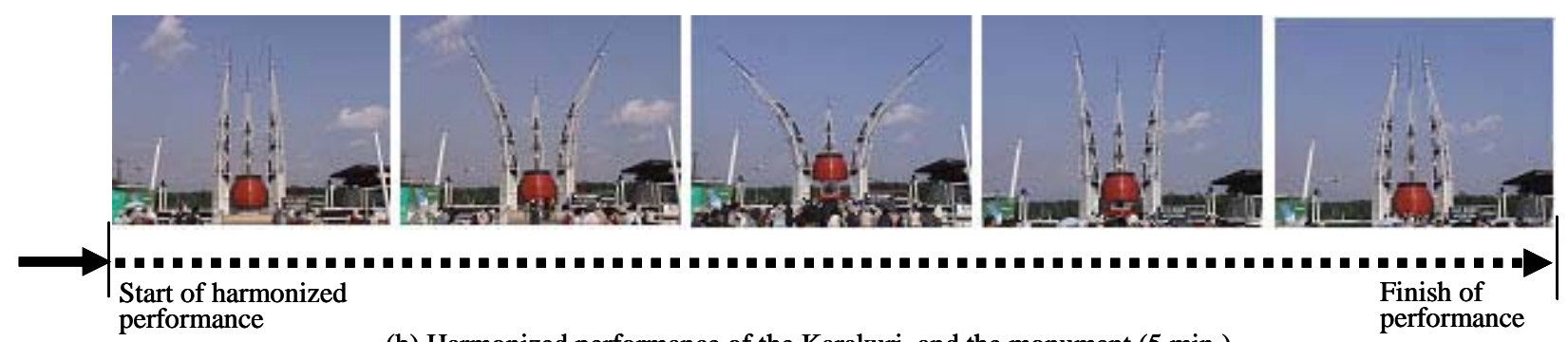

(b) Harmonized performance of the Karakuri and the monument (5 min.)

Figure 11 Shape changes of monument according to performance patterns 
minutes, that is, only the monument was moved for the 25 minutes of the first part, and the Karakuri doll danced with the monument for the 5 minutes of the second part. This performance loop was continuously repeated

For the monument's performance, there were two program modes. In the normal mode, the velocity and the stopping time of the actuator rod were decided by measuring and analyzing the state of the natural data (wind velocity, temperature, time, day and so on). As a result, the entire monument was moved to produce very irregular shape changes, as indicated in Figure11-(a). There was a little case in which the shape of three towers reappeared at the same time. In a special mode, the monument was moved at high speed to accompany a pre-install program. This mode, being outside the performance loop, started suddenly, so nobody was expecting it. By selecting such modes, it was possible to express very interesting movements and monument shapes that changed slowly but dynamically.

On the other hand, in the coordinated performance with the Karakuri doll, the monument was opened and closed powerfully, synchronizing with the Karakuri doll's performance, as indicated in Figure11(b). In this case, the Karakuri doll performed a variable dance and somersaults with sound and illumination effect. A very traditional but innovative performance was thus created. In this performance, the Karakuri doll was the main player and the monument was a supporting player.

\subsection{Monument operation}

During the Expo, the monument was operated continuously for about 13 hours a day. However, its operation was modified every day and at times when there were unexpected special events. Figure 12 shows the record of operation frequency each day and their accumulations. When the shape of the monument was changed to open and to close, the operation was counted as one.

At the beginning of the Expo, the average speed at which the monument moved was set at a low level, and the speed was changed depending on the day of the week. Two months after opening, the performance was switched to a random mode program. The operation frequency was observed to be almost constant. During the last month, the average speed approached the maximum level corresponding to the upsurge in attendance at the Expo site. During the Expo, the monument was operated continuously for 185 days, except during maintenance or thunderstorms, and there were neither breakdowns nor accidents. By the end of the Expo, there had been 50000 operations, thus confirming that the monument was operated within the range of the initial plan.

After the Expo ended, the monument and other devices were temporarily removed from the site. In response to demands for its reconstruction, it was reconstructed in the field of the company that manufactured the VGT actuator, and is now open to the public as a memorial tower to the Expo. It may continue operating forever.

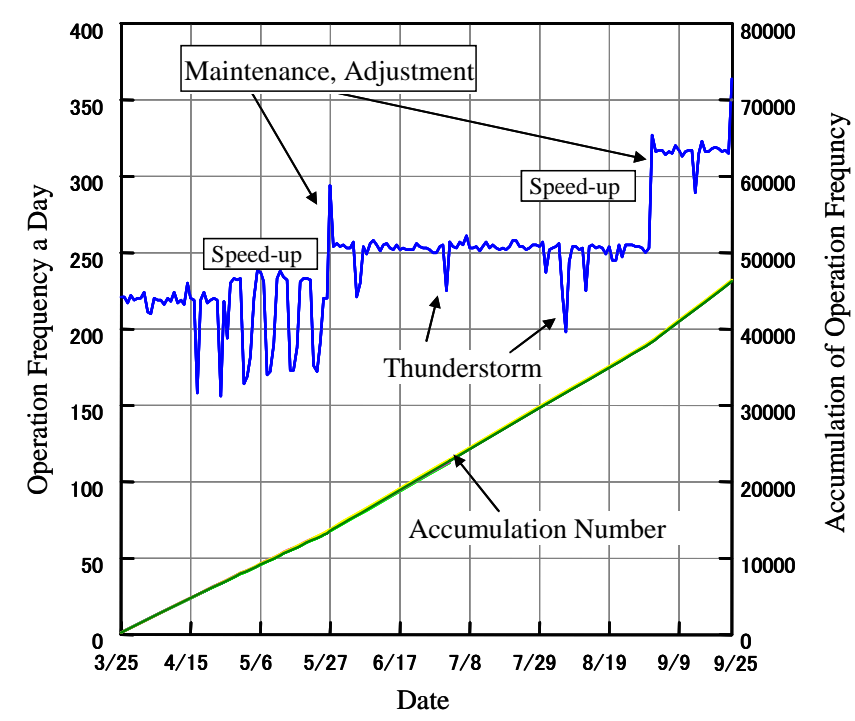

Figure 12 Record of monument's operation frequency during the Expo

\section{CONCLUSION}

The application process for the movable monument with the VGT as an adaptive structure element and the operation conditions at the Expo 2005 were reported. This was the first big project since the VGT technology had been developed in the construction field. In the application of the monument, we considered quality and security of construction. As a result, safe and excellent continuous performance was achieved, and the monument received high praise from promoters and many visitors.

The VGT was shown to be a very useful technology for such movable structures whose shape can be changed variably. In the future, with progressing and spreading of VGT technology, we will propose various applications.

Finally, the authors thank all who supported the development and application of the movable monument at Expo 2005.

\section{REFERENCES}

[1] K. Ishii et al, "Moving Architecture". Journal of Architecture and Building Science, 110, 1995, pp.3 - 44

[2] M. C. Natori and K. Miura, "Development of truss concept in Space Technology”, Proc. of International Symposium on Membrane Structure and Space Frame, 1986, pp.45-56.

[3] K. Kurita and F. Inoue et al, "Development of Adaptive Roof Structure by Variable Geometry Truss” Proc. of 18th International, Symposium on Automation and Robotics in Construction, 2001, pp.63-68.

[4] F. Inoue, K. Kurita, Y. Utsumi and N. Furuya, "Application of Adaptive Structure And Control by Variable Geometry Truss", Proc. of The CIB 2003 International Conference on Smart and Sustainable Built Environment, 2003, pp.59. 